\title{
Deep Brain Stimulation in Sub-Thalamic Nucleus in idiopathic Parkinson's disease - our initial experience in four cases
}

\author{
Raihan MZ, Aziz TZ
}

Conflict of interest: There is no conflict of interest relevant to this paper to disclose.

Funding Agency: Was not funded by any institute or any group.

Contribution of Authors: Raihan MZ was Principal investigator, Aziz TZ help for protocol preparation,

Copyright: @2019 Bang. JNS published by BSNS. This article is published under the creative commons CC-BY-NC license.

This license permits use distribution (https://creativecommons.orgf/ licences/by-nc/4-0/) reproduction in any medium, provided the original work is properly cited, and is not used for commercial purposes.

Received: 15 January, 2019

Accepted: 29 January, 2019

\begin{abstract}
:
Parkinson's Disease ( $P D)$ is a chronic neurodegenerative disease. It's cardinal features are resting tremor, Rigidity, Akinesia and postural instability. Idiopathic Parkinson's disease develops mainly due to degeneration of Dopaminergic neurons of Substantia Nigra. The role of Subthalamic Nucleus ( STN) in the development of Parkinsonian Tremmor and other cardinal features is not completely understood yet. However previous studies in monkeys, administration of MPTP (1-methyl-4-phenyl1.2.3.6.-tetrahydropyridine) proved that sub thalamic nucleus has a direct role in the development of Parkinsonian tremor and other features. We used no Micro Electrode Recording (MER) system,only studied clinically that Parkinsonian tremor stopped immediately after placement of electrode and same thing happened after micro stimulation of the sensorymotor region of the sub thalamic nucleus. Then high frequency deep brain stimulation (DBS) of these same four patients were assessed six months after surgery which led to a significant reduction of Parkinsonian tremor as well as other cardinal features of $P D(\mathrm{p}<0.001)$. Both postural and resting tremor disappeared completely in three cases and significantly reduced in one case.
\end{abstract}

Key words:Subthalamic Nucleus(STN), Deep Brain Stimulation(DBS), Ventralis Intermedius Nucleus(VIM), Parkinson's Disease(PD), Unified Parkinson's Disease Rating Scale(UPDRS), 1-methyl-4-phenyl-1.2.3.6.-tetrahydropyridine(MPTP)

Bang. J Neurosurgery 2019; 9(1): 78-83

\section{Introduction:}

Parkinson, $\mathrm{s}$ disease is a chronic disabling neuro degenerative disorder characterized by resting tremor , akinesia , rigidity and postural instability caused mainly by degeneration of Dopaminergic neurons of Substantia Nigra ${ }^{1}$. In the early stage of disease , Levodopa and/or Levodopa agonist drugs improves dramatically the motor symptoms of Parkinson's disease but after few years, this treatment is eventually hampered by increasing the motor complications - such as "wearing-off ", "on" or "of " phenomena ${ }^{2}$; even, as well as, troublesome drug induced dyskinesia ${ }^{3}$. Before introduction of drugs in early sixties, surgical lesioning procedures specially Pallidotomies and Thalamotomies were applied to improve these symptoms but often, it was at risk of development of irreversible and severe side effects like dysarthria or hemiparesis in unexperienced hands . Bilateral lesioning surgery dramatically increased complications and was there rarely performed ${ }^{4}$.
Deep Brain Stimulation (DBS ) in the motor thalamusthe Ventral Intermedius Nucleus ( VIM ) was first introduced in 1986 to treat the medically refractory tremor in $\mathrm{PD}^{4}$. DBS of various basal ganglia nucleus has shown to be highly effective in the treatment of several movement disorder ${ }^{5}$. Traditionally, in tremor the target nucleus is VIM , in hyperkinesia, the nucleus is Globus Pallidus Internus ( GPi ) and generally in PD features, the target nucleus is Sub Thalamic Nucleus ( STN ) were found to be safe and effective ${ }^{6}$.

Compared with lesioning, uni or bi lateral DBS is found to develop no or minimal tissue damage or complications and the main difference is that it is reversible ${ }^{7}$. In course of disease, the stimulation parameters can be changed as needed to maintain the corrected PD features ${ }^{8}$. In different randomized controlled trial DBS showed a better functional outcome with fewer side effects and therefore, DBS surgery replaces almost completely the lesion in developed countries. However . due to economic

1. Dr. Md. Zahid Raihan, Associate Professor \& Head, Department of Neurosurgery, Kushtia Medical College .

2. Dr. Tipu Zahed Aziz, Professor of Functional Neurosurgery,Jhon Radcliffe Hospital, University of Oxford , UK

Address of Correspondence: Dr. Md. Zahid Raihan, Associate Professor \& Head, Department of Neurosurgery, Kushtia Medical College.E-mail: 1967zahidraihan.zr@gmail.com 
restriction in particular countries like Bangladesh , lesion still might be the only option? .

Particularly, which nucleus causes tremor in Parkinson's Disease (PD) is still a matter of debate . Initially, it was thought that Ventralis Intermedialis Nucleus (VIM) is the only nucleus closely associated with tremor in $\mathrm{PD}^{10}$. The development of the 1-methyle4-phenyl-1.2.3.6-tetrahydropyridine (MPTP) model of $\mathrm{PD}$ in monkey shows that there develops new physiologic resting and postural tremmors ${ }^{11}$. This study indicates that gross deficiency of Dopamine as induced by repeated administration of MPTP, may develop PD in monkey as PD develop in human being ${ }^{11}$. Also in such animal study, though it was shown that tremor in the limbs is associated with oscillatory neuronal discharges in the Globus Pallidus externus (GPe), Globus Pallidus Internus (GPi) and Sub Thalamic Nucleus (STN), lesion of the STN reduced or even abolished the tremor in MPTP monkeys ${ }^{13}$. Tremor arrest was indeed the earliest and most reliable sign of a therapeutically effective lesion of the STN in MPTP monkeys. Long term stimulation of STN in Parkinsonian monkey was also accompanied by supression of tremor. Despite such experimental evidence, Ventralis Intermedius ( VIM ) nucleus of thalamus was still the only target nucleus for many years for the control of tremor and STN was completely ignored ${ }^{14,15}$.

There is, however, no scientific reason to ignore the STN in the mechanism of tremor and other cardinal features in PD and therefore, now it becomes the main target nucleus for deep brain stimulation in PD patients ${ }^{16}$.

In this article, we provide the clinical evidence and therapeutic effect of DBS in STN in controlling the tremor and other cardinal features of $P D^{17,18,19}$.

\section{Patient selection:}

In selecting the appropriate patient, risk versus benefit should be assessed carefully .Parkinsonian syndrome improves by DBS only when it is Levodopa responsive idiopathic $P D^{20}$. Except tremor, responsiveness to DBS of all other cardinal features are variable. Initially all motor symptoms respond very well to Dopaminergic medication but after few years lead to long term motor complications like disabling drug induced dyskinesia, wearing off , off or on phenomenon etc $3,21,22$. About $50 \%$ drug non-responsiveness and motor fluctuation develop after a mean of 5 years of treatment and it is high in young patients. Levodopa sensitive off symptoms; Levodopa induced dyskinesia and Tremorthese three features are well controlled by $\mathrm{DBS}^{23}$.

Concerning STN-DBS, Dopamine responsiveness has the highest predictive value for a good and persistent motor outcome with stimulation and symptoms resistance to Dopamine are typically resistance to DBS also $24,25,4$. In Levodopa challenge test, if there is improvement of motor symptoms in at least 30\% comparing to "off "state , DBS will be beneficial . "off " state assessment is performed after withdrawal of all medications for at least 12 hours. Then 1.5 times usual effective morning dose is given to assess the "on "state motor score . At least 30\% motor score improvement is desirable compare to off state motor score as assessed by Unified Parkinson's Disease Rating Score (UPDRS ) for a successful outcome after DBS $26,27,28.50 \%$ improvement of UPDRS motor score in Levodopa challenge test is shown to have best outcome. A low responsiveness to Levodopa is associated with post operative cognitive decline ${ }^{25,27}$. "Off" phase should cover at least $25 \%$ of awake time and should have minimum severity of 30/108 point on UPDRS motor score 28 . Peak -dose-hyperkinesias and biphasic dyskinesias as well as OFF-dystonia respond well to DBS. Severe disabling tremor is the only symptom which, upto 80 to $90 \%$, shows excellent response to DBS even with Levodopa resistance. And that,s why , tremor is therefore a good target symptom for STN-DBS ${ }^{29,30}$.

During the best medical ON state, if Freezing of gait, postural instability and dysarthrophonia persist, there will be no significant improvement after STN-DBS ${ }^{26,27}$. Atypical Parkinsonian syndrome, e.g. Multiple System Atrophy, Progressive Supra Nuclear Palsy show transient or no response to DBS ${ }^{31}$. Although sometimes bladder function may improve slightly after DBS, early autonomic involvementindicates atypical Parkinsonian symptoms and should be avoided for DBS ${ }^{32}$.

Another parameter is age for successful outcome of DBS surgery, e.g. biological age shows an inverse correlation with the improvement of motor function $26,27,33,34$.

Finally, prior to implanting DBS electrodes evaluation of cognitive function and Neuropsychiatric symptoms is of crucial importance, because, in that case DBS is contraindicated.

\section{Target points:}

STN is the main target nucleus for DBS in PD. All cardinal symptoms that respond well to Levodopa , including akinesia, rigidity, tremorand postural instability can be effectively treated by STN-DBS ${ }^{33,34}$. The best outcome achieved by stimulation of the dorsolateral motor part of the STN but some times zona incerta shows good results ${ }^{35,36}$.

Levodopa induced dyskinesia improved by implanting DBS electrode at Globus Pallidus Internus (GPi) nucleus $^{37,38}$. The effect on OFF-symptoms might be 
less pronounced. However, the excellent reduction of dyskinesias allows a further increase of Dopaminergic medications $39,40,33$

In PD patients, only tremor can be immediately and effectively controlled by implanting DBS electrode in Ventralis Intermedius Nucleus ( VIM ) of Thalamus but there is no effect on akinesia and rigidity. Therefore , VIM-DBS is performed in PD patients only in older age group people with unilateral tremor dominant $\mathrm{PD}^{5}$.

The Pedunculopontine Nucleus (PPN) has recently came to the target point of interest of DBS implantation in early as well as late PD ${ }^{41}$.

\section{Patients and Methods}

Deep Brain Stimulation

4 patients with $\mathrm{PD}$, all of who had tremor and other cardinal features of PD e.g. rigidity, akinesia and postural instability and their motor complications were uncontrollable by the available therapeutic approaches were surgically treated by implanting electrodes in STN for long term stimulation.Pre operativecharacteristics of the patients are summarized in table 1. The Unified Parkinson Disease Rating Scale ( UPDRS ) was used for global pre and post operative evaluation. For postoperative evaluation we assessed after six months.Preoperative "ON" and "OFF" state UPDRS were scored to select the ideal patient for Deep Brain Stimulation ( DBS ) surgery. The "OFF " was defined as motor assessment after 12 hours without antiparkinsonian drugs and "ON" is defined as motor evaluation after injestion of one and half times the usual optimum morning dose of Levodopa e.g on the basis of "Levodopa challenge test ". Minimum 30\% improvement in UPDRS scoring at ON state comparing with the OFF state were selected for DBS surgery.

\section{Procedure and targeting the STN}

Firstly, we do very high resolution MRI in different sequences specially $\mathrm{T} 1$ and $\mathrm{T} 2$ at $1 \mathrm{~mm}$ interval. Then we used the navigation soft ware "Neuroinspire "to calculate the coordinates $\mathrm{X}, \mathrm{Y}, \& \mathrm{Z}$ for targeting the dorso-lateral STN nucleus. Then after fixing the Leksell frame to patient's head we do a CT scan . This CT scan and previously done MRI we fuse digitally in the same Neuroinspire soft ware and finally we re-establish those $X, Y \& Z$ coordinates in relation to the same patient's head. Finally after fixing the frame to the OT table and under local anaesthesia we insert two electrodes in two (Right \& Left) Subthalamic Nucleus (STN) in each patient. Immediate after insertion temporarily the tremor goes away due to mechanical injury to the nucleus by the electrodes. Then we check the impedance of those electrodes and finally check the correct position of the electrodes by doing an another CT scan And lastly we connect these electrodes to the battery placed underneath the skin of left chest wall under general anaesthesia.

It is to be noted that the subthalamic nucleus (STN) is an almond shaped nucleus. For targeting the STN, the average coordinates are $2-3 \mathrm{~mm}$ behind the midcommissural point (AC-PC line), that is called $Y$ axis . 12-14 mm either right or left lateral to $A C-P C$ is $X$ axis and 4 to $6 \mathrm{~mm}$ below the $A C-P C$ is $Z$ axis .

\section{Clinical result}

We treated four patients with bilateral STN stimulation and assessed after six months. Stimulation parameters were -Amplitude range from $1.5 \mathrm{~V}$ to $4 \mathrm{~V}$ ; Pulsewidth range from 90 to $120 \mathrm{~ms}$ and Frequency from 120 to $180 \mathrm{~Hz}$. Assessment at six month was carried out.

There was marked reduction of tremor both at rest and during action in all patients ( Table2). Same efficacy reported by Crack et al., in terms of tremor reduction by DBS monitored for 3-6 months.

Table-I

Patients selected for STN-DBS ( $n=4$ )

General criteria for selection

\begin{tabular}{lccccccccc}
\hline $\begin{array}{l}\text { Patient } \\
\text { No. }\end{array}$ & Sex & $\begin{array}{c}\text { Age } \\
\text { (yrs) }\end{array}$ & $\begin{array}{c}\text { PD } \\
\text { (yrs) }\end{array}$ & $\begin{array}{c}\text { LDopa } \\
\text { (yrs) }\end{array}$ & $\begin{array}{c}\text { LDopa } \\
\text { Dose(mg) }\end{array}$ & $\begin{array}{c}\text { Tremor } \\
\text { Score (OF) }\end{array}$ & $\begin{array}{c}\text { Tremor } \\
\text { Score(ON) }\end{array}$ & $\begin{array}{c}\text { UPDRS } \\
\text { OF }\end{array}$ & $\begin{array}{c}\text { UPDRS } \\
\text { ON }\end{array}$ \\
\hline 1 & $\mathrm{~F}$ & 62 & 12 & 11 & 1100 & 22 & 10 & $4743.51 \%$ & $3027.77 \%$ \\
2 & $\mathrm{M}$ & 65 & 10 & 9 & 1400 & 23 & 12 & $5651.85 \%$ & $3532.40 \%$ \\
3 & $\mathrm{~F}$ & 58 & 9 & 9 & 1000 & 20 & 10 & $4541.66 \%$ & $3128.70 \%$ \\
4 & $\mathrm{M}$ & 42 & 12 & 11 & 825 & 18 & 8 & $4339.81 \%$ & $3027.77 \%$ \\
\hline
\end{tabular}

STN, sub thalamic nucleus; PD, Parkinson,s Disease ; UPDRS, Unified Parkinson,s Disease Rating Scale ; DBS , Deep Brain Stimulation

Tremor Score Maximum=33 
Table-II

Tremor reduction by DBS in the STN assessed by tremor score

\begin{tabular}{lcc}
\hline Patient no. & Tremor score $(\mathrm{R}+\mathrm{P})^{*}$ & $\begin{array}{c}\text { Postoperative } \\
\text { after six months }\end{array}$ \\
\hline 1 & 22 & 0 \\
2 & 23 & 1 \\
3 & 20 & 0 \\
4 & 18 & 0 \\
\hline
\end{tabular}

DBS, deep brain stimulation; STN, sub thalamic nucleus; $\mathrm{R}+\mathrm{P}$, resting + postura Tremor score was maximum 33.

Table-III

Clinical improvement by STN-DBS assessed by UPDRS motor score

\begin{tabular}{|c|c|c|c|c|}
\hline $\begin{array}{l}\text { UPDRS } \\
\text { before } \\
\text { surgery } \\
\text { OFF state }\end{array}$ & $\begin{array}{c}\text { UPDRS } \\
\text { before } \\
\text { surgery ON } \\
\text { state }\end{array}$ & $\begin{array}{c}\text { UPDRS after } \\
\text { DBS } \\
\text { (six months } \\
\text { after surgery) }\end{array}$ & $\begin{array}{c}\text { UPDRS } \\
\text { improved } \\
\text { by DBS } \\
\text { surgery(\%) }\end{array}$ & $\begin{array}{c}\text { Average } \\
\text { Improvement }\end{array}$ \\
\hline $47(43.51 \%)$ & $30(27.77 \%)$ & $18(16.66 \%)$ & $61.70 \%$ & $63.33 \%$ \\
\hline $56(51.85 \%)$ & $35(32.40 \%)$ & $20(18.51 \%)$ & $64.30 \%$ & $(p<0.001)$ \\
\hline 45 ( $41.66 \%)$ & $31(28.70 \%)$ & 17 (15.74 \%) & $62.21 \%$ & \\
\hline $43(39.81 \%)$ & 30 ( $27.77 \%)$ & $15(13.88 \%)$ & $65.13 \%$ & \\
\hline
\end{tabular}

STN, subthalamic nucleus ; DBS, deep brain stimulation ; UPDRE, unified Parkinson,s disease rating scale UPDRS motor score maximum 108

Not only the tremor but also the other cardinal features like rigidity, bradykinesia were also improved. And along with the limb movements, body posture, gait , walk, standing from chair, facial expression, speech, swallow, memory were all improved by DBS. All these were assessed by UPDRS score and shown in table 3. The UPDRS score decreased in "OFF " period average by $63.33 \%$ ( $p<0.001$ ) along with the Levodopa dose reduced significantly.

There was no significant post-operative complications only mild depression developed in one patient.

\section{Discussion:}

In general, the tremor related neuronal activity, microstimulation intraoperatively and after that long term high frequency stimulation prove that STN is the important structure in the mechanism of tremor in PD though whether the STN plays the primary role or mediate the other basal ganglionic structure to do the such, it is still not clear.

VIM is the well stablished structure in development of PD and MPTP monkey ${ }^{17,20}$. Positron Emmission Tomography (PET) shows that there is increase blood flow in cerebellar vermis, sensory motor area , premotor cortical area in PD tremor which is similar to any type of "Tremor Like " repetitive movement in normal people. These areas show decreased blood flow after DBS in VIM ${ }^{44}$. Though Cerebellum and VIM are not connected directly to basal ganglia structures and hardly considered as tremor producing structures in Parkinson,s disease.

Dopamine depletion results in reduced inhibition of the Gaba-amino - butyric - acid (GABA) which causes excessive inhibition of the Globus Pallidus Externa $(\mathrm{GPe})$ which causes functionally hypoactivity. Normally there is a reciprocal balance berween GPe inhibitory activity and the excitatory effect of STN. Excessive GPe inhibition leads to increased firing rate in STN. The oscillatory low frequency firing cluster cells inGPe due to reduced inhibition results in excessive STN activity which could only be abolished by inactivating the cortex ${ }^{14}$.

All these above observations indicates that STN have the property of discharge in brust in Dopamine deficiency. Furthermore, the STN not only exerts the excitatory effect on both Globus Pallidum (GP) 
components but also control synchronizinglarge number of GP neurons. We therefore suggest that tremor in PD is well controlled by DBS in $\mathrm{STN}^{9}$. Though, still there is no exclusive available data regarding the origin of oscillation in basal ganglia , but hopefully, in future, there will be available data to change the view that VIM in thalamus may not be the cause of tremor and STN is the only structure for DBS to control the tremor in $\mathrm{PD}^{11,19,39}$.

Grenoble's group shows that, though the initial effect of DBS in STN or VIM to control tremor in PD is same , in case of VIM DBS, after 5-10 years, there develops severe dyskinesias and "OFF" episodes. On the contrary, STN stimulation improves all cardinal features of PD without complications in long term follow-up. All these suggest that, STN might be the effective target considered for the treatment of all cardinal features if $\mathrm{PD}$ with mainly the severe $P \mathrm{P}^{16,18,19}$.

\section{Conclution:}

Till today, excellent result can only be achieved through STN-DBS to control the all cardinal features of PD including severe tremor .Except only in few cases of severe unilateral tremor with extreme age, the VIM nucleus of thalamus or in cases of severe dyskinesias, Globus Pallidus Internus (GPi) might be the target nucleus .

\section{References:}

1. Hughes, A.J., Ben-Shlomo, Y., Daniel, S.E. and Lees, A.J. (1992) What features improve the accuracy of clinical diagnosis in Parkinson's disease: a clinicopathologic study. Neurology 57: S34-38.

2. Goetz, C.G., Poewe, W., Rascol, O. and Sampaio, C. (2005) Evidence-based medical review update: pharmacological and surgical treatments of Parkinson's disease: 2001 to 2004. Mov Disord 20: 523-539.

3. Ahlskog, J.E. and Muenter, M.D. (2001) Frequency of levodopa-related dyskinesias and motor fluctuations as estimated from the cumulative literature. Mov Disord 16: 448-458.

4. Benabid, A.L., Pollak, P., Louveau, A., Henry, S. and de Rougemont, J. (1987) Combined (thalamotomy and stimulation) stereotactic surgery of the VIM thalamic nucleus for bilateral Parkinson disease. Appl Neurophysiol 50: 344-346.

5. Benabid, A.L., Pollak, P., Gao, D., Hoffmann, D., Limousin, P., Gay, E. et al. (1996) Chronic electrical stimulation of the ventral intermedius nucleus of the thalamus as a treatment of movement disorders. J Neurosurg 84: 203214.

6. Deuschl, G., Schade-Brittinger, C., Krack, P., Volkmann, J., Schafer, H., Botzel, K. et al. (2006) A randomized trial of deep-brain stimulation for Parkinson's disease. N Engl J Med 355: 896-908.

7. Pilitsis, J.G., Chu, Y., Kordower, J., Bergen, D.C., Cochran, E.J. and Bakay, R.A. (2008) Postmortem study of deep brain stimulation of the anterior thalamus: case report. Neurosurgery 62: E530-E532.

8. Kuncel, A.M. and Grill, W.M. (2004) Selection of stimulus parameters for deep brain stimulation. Clinical Neurophysiology 115: 2431-2441.

9. Burbaud, P., Vital, A., Rougier, A., Bouillot, S., Guehl, D., Cuny, E. et al. (2002) Minimal tissue damage after stimulation of the motor thalamus in a case of chorea-acanthocytosis. Neurology 59: 1982-1984

10. Lenz FA, Kwan HC,Dostrovosky IO, Tasker RP, Murphy JT, Lenz YE. Single unit Analysis of humal ventral thalamic nucleus group. Brain 1990:113:1795-1821.

11. Bergman H, Wichmann T, Karmon B, Delong MR. The primate subthalamic nucleus. II: Neuronal activity in the MPTP model of parkinsonism. J Neurophysiol 1994;72:507520.

12. Lenz FA, Vitek JLDeLOng MR,. Role of the thalamus in Parkinsonian tremor: evidence from studies in patients and primate models. Stereotact Funct Neurosurg 1992:60:94-103.

13. Wichmann T, Bergman H, DElong MR. The primate subthalamic nucleus III: Changes in motor behavior and neuronal activity in the internal pallidum induced by subthalamic inactivation in the MPTP model of parkinsonism. J Neurophysiol 1994:72:521-530.

14. Aziz TZ, Peggs D, Agarwal E, Sambrook MA, Crossman AR. Subthalamic neucleotomy alleviates parkinsonism in the 1-methyl-4-phenyl-1,2,3,6-tetrahydropyridine (MPTP)exposed primate. $\mathrm{Br}$ J Neurosurg 1992:6:575-582.

15. Guridi J, Herrero MT, Lukuin MR, et al. Subthalamotmy in parkinsonian monkey: behavioural and biochemical analysis. Brain 1996;119;1717-1727.

16. Narabayashi $\mathrm{H}$, Stereotactic vim thalamotomy for treatment of tremor. Eur Neurol 1989:29:29-32.

17. Sellal F, Hirsch E, Lisovoski F, Mutscholer V, Collard M , Marescaux C. Contralateral disappearance of parkinsonian signs after subthalamic haematoma. Neurology 1992:42:244-256.

18. Cardose F, Jankovic J, Grossman RG , Hamilton WJ. Outcome after stereotacticthalamotomyfor dystonia and heibalismus. Neurosurgery 1995;36:501-508.

19. Vidakovic A, Dragasvic N, Kostic JS. Hemibalism: report of 25 cases. J Neurol Neurosurg Psychiatry 1994:57:945949.

20. Moro, E., Volkmann, J., Ko"nig, I.R., Winkler, S., Hiller, A. and Hassin-Baer, S. (2008) Bilateral subthalamic stimulation in Parkin and PINK1 parkinsonism. Neurology 70: 11861191.

21. LeWitt, P.A. (2008) Levodopa for the treatment of Parkinson's disease. N Engl J Med 359: 24682476.

22. Olanow, C.W., Watts, R.L. and Koller, W.C. (2001) An algorithm (decision tree) for the management of Parkinson's disease: treatment guidelines. Neurology 56: S1S88. 
23. Rascol, O., Brooks, D.J., Korczyn, A.D., De Deyn, P.P., Clarke, C.E. and Lang, A.E. (2000) A five- year study of dyskinesia in patients with early Parkinson's disease who were treated with ropinirole or levodopa. 056 Study Group. N Engl J Med 342: 14841491.

24. Pahwa, R., Factor, S.A., Lyons, K.E., Ondo, W.G., Gronseth, G., Bronte-Stewart, H. et al. (2006) Practice Parameter: Treatment of Parkinson disease with motor fluctuations and dyskinesia (an evidencebased review): Report of the Quality Standards Subcommittee of the American Academy of Neurology. Neurology 66: 983-995.

25. Kleiner-Fisman, G., Fisman, D.N., Sime, E., Saint-Cyr, J.A., Lozano, A.M. and Lang, A.E. (2003) Long term follow up of bilateral deep brain stimulation of the subthalamic nucleus in patients with advanced Parkinson's disease. J Neurosurg 99: 489495 .

26. Charles, P.D., Van Blercom, N., Krack, P., Lee, S.L., Xie, J., Besson, G. et al. (2002) Predictors of effective bilateral subthalamic nucleus stimulation for PD. Neurology 59: 932934.

27. Welter, M.L., Houeto, J.L., Tezenas du Montcel, S., Mesnage, V., Bonnet, A.M., Pillon, B. et al. (2002) Clinical predictive factors of subthalamic stimulation in Parkinson's disease. Brain 125: 575-583.

28. Hilker, R., Benecke, R., Deuschl, G., Fogel, W., Kupsch, A., Schrader, C. et al. (2009) Deep brain stimulation for Parkinson's disease: Consensus recommendations of the German Deep Brain Stimulation Association. Nervenarzt Epub ahead of print.

29. Krack, P., Pollak, P., Limousin, P., Benazzouz, A., Deuschl, G. and Benabid, A.L. (1999) From offperiod dystonia to peak-dose chorea. The clinical spectrum of varying subthalamic nucleus activity. Brain 122: 1133-1146.

30. Krack, P., Pollak, P., Limousin, P., Benazzouz, A. and Benabid, A.L. (1997) Stimulation of subthalamic nucleus alleviates tremor in Parkinson's disease. Lancet 350: 1676.

31. Lang, A.E., Houeto, J.L., Krack, P., Kubu, C., Lyons, K.E., Moro, E. et al. (2006) Deep brain stimulation: preoperative issues. Mov Disord 21: S171-S196.
32. Herzog, J., Weiss, P.H., Assmus, A., Wefer, B., Seif, C., Braun, P.M. et al. (2006) Subthalamic stimulation modulates cortical control of urinary bladder in Parkinson's disease. Brain 129: 3366-3375.

33. Weaver, F.M., Follett, K., Stern, M., Hur, K., Harris, C., Marks Jr, W.J. et al. (2009) Bilateral deep brain stimulation vs best medical therapy for patients with advanced Parkinson disease: arandomized controlled trial. JAMA 301: 63-73.

34. Voges, J., Hilker, R., Bo" tzel, K., Kiening, K.L., Kloss, M., Kupsch, A. et al. (2007) Thirty days complication rate following surgery performed for deep-brainstimulation. Mov Disord 22: 1486-1489.

35. Herzog, J., Fietzek, U., Hamel, W., Morsnowski, A., Steigerwald, F., Schrader, B. et al. (2004) Most effective stimulation site in subthalamic deep brain stimulation for Parkinson's disease. Mov Disord 19: 1050-1054.

36. Kumar, R., Lozano, A.M., Sime, E., Halket, E. and Lang, A.E. (1999) Comparative effects of unilateral and bilateral subthalamic nucleus deep brain stimulation. Neurology 53 : 561566.

37. Okun, M.S., Fernandez, H.H., Wu, S.S., KirschDarrow, L., Bowers, D., Bova, F. et al. (2009) Cognition and mood in Parkinson's disease in subthalamic nucleus versus globus pallidus interna deep brain stimulation: The COMPARE Trial. Ann Neurol Epub ahead of print.

38. Weaver, F., Follett, K., Hur, K., Ippolito, D. and Stern, M. (2005) Deep brain stimulation in Parkinson disease: a metaanalysis of patient outcomes. J Neurosurg 103: 956967.

39. Volkmann, J., Allert, N., Voges, J., Sturm, V., Schnitzler, A. and Freund, H.J. (2004) Long-term results of bilateral pallidal stimulation in Parkinson's disease. Ann Neurol 55: 871-875.

40. Volkmann, J., Allert, N., Voges, J., Weiss, P.H., Freund, H.J. and Sturm, V. (2001) Safety and efficacy of pallidal or subthalamic nucleus stimulation in advanced PD. Neurology 56: 548-551.

41. Stefani, A., Lozano, A.M., Peppe, A., Stanzione, P., Galati, S., Tropepi, D. et al. (2007) Bilateral deep brain stimulation of the pedunculopontine and subthalamic nuclei in severe Parkinson's disease. Brain 130: 15961607. 